\title{
A Problemática Aceitação Social da Noção DE INATISMO NA COGNIÇÃo DE LINGUAGEM
}

\author{
Why is innatism socially unacceptable with respect \\ to the knowledge of language?
}

\author{
Miriam Lemle
}

PRólogo

Se o fazer científico fosse motivado pelo puro desejo de compreender cada vez melhor como o universo é, a trabalheira toda somente faria sentido se almejar a verdade sobre "como o universo é" fosse uma meta sensata. Em Knowledge of Language, its Nature, Origin and Use, livro publicado em 1996, Chomsky põe em contraste dois problemas filosóficos antagônicos, a que denomina de problema de Platão e problema de Orwell. Ele dividiu o livro em duas partes, dedicando cada uma a um destes dois problemas epistemológicos. Na primeira parte, Chomsky apresenta a teoria da gramática gerativa como uma modalidade do "problema de Platão". Usou essa expressão por considerar que o filósofo grego, ao salientar que as pessoas possuem conhecimentos que não têm origem a partir de sua experiência direta, antecipara o espaço do inatismo, hipótese que Chomsky considera, na história da epistemologia, um substituto viável para a hipótese do retorno das almas, aventada há 24 séculos por Platão. A segunda parte de Knowledge of Language é intitulada o problema de Orwell, e é uma crítica à falta de hábitos críticos no pensamento político da sociedade americana atual, um pensamento que Chomsky considera uniforme, padronizado e deformador da realidade. O título desta parte do livro é uma referência ao escritor inglês George Orwell, autor dos celebrados romances 
Animal Farm e 1984, publicados logo depois do fim da Segunda Guerra Mundial, caricaturas do poder autoritário, abusivo e arbitrário que gera criaturas cruéis e robôs submissos e opressos.

\section{INTRODUÇÃo}

A etologia, a ciência que estuda o comportamento dos animais, vem apontando para um caminho análogo ao da gramática gerativa para a compreensão das capacidades cognitivas dos animais. Etologistas estão descrevendo capacidades cognitivas particulares de cada espécie animal, e para cada espécie estão procurando sistemas cognitivos tarefa-específicos. Estes mecanismos espécie-específicos e tarefa-específicos para a percepção do mundo constituem verdadeiros órgãos especializados para a captação e utilização de informações, "learning organs", no dizer de Charles Gallistel. Tais órgãos, fruto da evolução de cada espécie, seriam sistemas cognitivos pré-formatados com base em princípios inatos, que se implementam adequando-se a circunstâncias particulares: os dados da experiência. Vejamos alguns exemplos de estudos de etologia.

\section{MAPEAMENTO DO ESPAÇO POR INSETOS}

Observando a vida de formigas e abelhas, os etologistas concluem que ao saírem do formigueiro ou da colméia, em navegação à procura de alimento, elas efetuam e mantêem constantemente ativado um cálculo a respeito da relação entre o ponto de partida e o ponto onde presentemente se encontram, até o instante em que descobrem uma fonte de alimento. Os insetos fazem isso com base em um saber inato sobre onde é o norte, e usam no mapeamento a posição do azimute solar - o ponto em que a linha vertical traçada a partir da posição do sol cruza com a linha do horizonte. Esse ponto é mapeado em relação com o ponto de partida - colméia ou formigueiro - e com a posição em que estão a cada instante. Os insetos voltam para casa guiados por seu mapa, e ao chegarem lá executam um ritual em que sinalizam para as companheiras o lugar onde há alimento. A sinalização das abelhas consiste de um vôo em forma de oito, no plano vertical, que rebatido para o plano horizontal representa, em relação à localização da colméia, o ângulo entre o azimute e a fonte. A intensidade e velocidade do vôo em oito codificam a qualidade do alimento e a medida da distância. As formigas expressam a informação por meio de um rebolado 
que demarca o ângulo entre o azimute e a fonte. Gallistel ressalta que a questão se complica se considerarmos que a posição do sol varia segundo as variáveis: latitude, estação do ano e hora do dia. Os pesquisadores constataram que os insetos sabem onde está o sol mesmo se o dia estiver nublado. Esta observação os leva a concluir que a aquisição da capacidade de localizar a fonte depende de um princípio constante - onde está o norte e parâmetros - a variação circunstancial do ângulo do azimute, segundo a hora do dia e a estação do ano naquela latitude. Os pesquisadores depreendem que a atualização da informação "hora do dia" é dada por um relógio biológico interno, o sistema circadiano. Este é o órgão que permite aos insetos calcularem onde está o sol a qualquer hora do dia, mesmo se estiver encoberto por nuvens.

Em situação experimental, abelhas foram criadas em cativeiro, impedidas de voar durante todo o dia, exceto nas quatro horas que precedem o por do sol. Sua experiência visual com o sol foi, desse modo, limitada a apenas vinte por cento da variação total do percurso do azimute. Depois de vários meses neste regime, algumas abelhas foram soltas durante a manhã, num dia nublado. Ao voltarem para a colméia, fizeram a dança do oito, e as companheiras puderam voar certeiramente para a fonte de pólen seguindo a direção dada na dança do oito. Se essas abelhas nunca tinham visto o sol da manhã, e se não o estavam vendo naquela manhã, como interpretar sua capacidade de traçar na dança a instrução correta para o vôo? A direção norte é um saber inato; o deslocamento do sol de leste para oeste é um saber inato; o relógio biológico que diz que horas são é inato. A reduzida experiência de ver o sol no final da tarde foi suficiente para que as abelhas pudessem calcular corretamente a posição do sol numa manhã nublada, e informar a direção do pólen fazendo a dança.

\section{RECURSIVIDADE NO CANTO DE ESTORNINHOS}

O canto dos pássaros é um outro campo de pesquisa ativo, que se vem apresentando como um caso fascinante da combinação de princípios gerais e parâmetros de variação a serem fixados pela experiência. Pássaros de cada espécie têm seus próprios padrões de canto, mas no interior de uma mesma espécie, entre diferentes nichos, há variações no canto: variação dialetal, portanto.

É fácil de ver as analogias entre as características dos conhecimentos dos animais e as propostas da teoria chomskiana de princípios e parâmetros. $O$ que depende de dotação geneticamente determinada num sistema de aprendizagem tarefa-específico corresponde aos Princípios. Então, 
o conhecimento da efeméride solar $=$ conhecimento de Princípios Universais da Gramática = filtro seletivo do canto de sua espécie nos pássaros selvagens.

Os parâmetros são os fatores que precisam ser adquiridos pela experiência. Então, ajustes requeridos por variações de latitude, estação do ano e hora do dia $=$ características particulares de línguas específicas $=$ particularidades dialetais no canto de cada espécie segundo a região.

\section{RECURSIVIDADE AssociadA À SEMÂNTICA NA LINGUAGEM HuMANA}

A polêmica filosófica que ronda essa área é exemplificada em um artigo recente, a respeito de canto de pássaros: Recursive syntactic pattern learning by songbirds, por Timothy Gentner e outros, publicado na revista Nature (v. 440, abr. 2006). O artigo relata que há padrões recursivos no canto dos estorninhos. Além disso, a equipe conseguiu treinar nove pássaros, num total de onze, para reconhecerem componentes recursivos em padrões musicais criados pelos treinadores, humanos. O cerne da polêmica é o seguinte. Num artigo na revista Science 22 (v. 298, n. 5598, p. 1569-1579, nov. 2002) intitulado The Faculty of Language: What is it, Who has it and How did it evolve, por Marc Hauser, Noam Chomsky e W. Tecumseh Fitch, os autores aventam que a recursividade seria uma propriedade exclusiva da sintaxe das línguas humanas. Gentner e seus co-autores, no artigo da Nature, afirmam que a capacidade de recursividade encontrada nos estorninhos contradiz a suposição de Chomsky e seus co-autores. A descoberta de que os estorninhos são capazes de produzir e apreender padrões recursivos implicaria em tornar os passarinhos mais próximos dos seres humanos em suas capacidades cognitivas. No entanto, Gentner et al. não mencionam qualquer contraparte semântica para os padrões recursivos dos estorninhos, o que nos autoriza a crer que a recursividade no canto dos pássaros seja uma propriedade atinente apenas à fonologia. Nas línguas humanas, porém, a sintaxe entrega as sentenças cuja derivação faz uso da recursividade para duas interfaces: a fonológica, que lê a forma fonológica, e a Semântica, que ao escanear a estrutura sintática fornece leituras semânticas que são em parte arbitrárias - via Enciclopédia - e em parte calculadas composicionalmente - via Forma Lógica. É estranho que os ornitologistas estejam minimizando esta diferença.

Assim, acabamos por ingressar num "problema de Orwell". A ciência da cognição envolve questões antropológicas tão interessantes quanto as questões internas que ela levanta. O que faz cientistas passarem ao largo da diferença crucial entre a recursividade puramente estrutural encontrada no canto dos estorninhos e a recursividade com contraparte semântica 
manifesta na computação em línguas humanas?

Vou encerrar com mais um exemplo de problema de Orwell.

\section{HÁ um MECANISMo GENÉRICO DE APRENDIZAGEM?}

o behaviorismo e a teoria das redes neuronais ou conexionismo compartilham a crença de que a conexão entre os dois estímulos dependeria de pareamento temporal da ativação, no condicionamento pavloviano, e de feedback ativado por erros a fim de ajustar forças de associação para reduzir erro, no caso de condicionamento instrumental. A necessidade de pareamento temporal significa que, para que o condicionamento se estabeleça, a unidade de tempo - segundos ou minutos - decorrida entre o estímulo não condicionado e o condicionado deve ser sempre a mesma.

Avaliando este modelo, Charles Gallistel põe em cheque a expectativa de que o intervalo entre o estímulo não condicionado e o condicionado seja uma medida de tempo constante. Gallistel ressalta que os paradigmas experimentais de condicionamento replicam involuntariamente problemas reais dos animais na natureza: são problemas de múltiplas variáveis, em série temporal não-estacionária. Problema multivariável significa que numerosos tipos de diferentes eventos prevêem a freqüência do estímulo não-condicionado, inclusive a ausência de eventos associados. Não-estacionário significa que as contingências entre estímulos mudam na linha do tempo, e a não-estacionariedade das contingências precisa ser levada em conta. A observação nova e crucial que Gallistel traz à cena é que o que os animais levam em conta não é um intervalo de tempo constante, mas sim uma taxa constante de contingência entre os dois estímulos. A janela de tempo pode ser variada em até dez vezes sem que o aprendizado seja afetado. Com base nestas observações Gallistel conclui que a noção de elo associativo deve ser substituída por um novo conceito: uma variável de decisão, que se baseia não mais na freqüência da conexão por unidade constante de tempo, mas sim na contingência dos estímulos. É a contingência que permite a decisão do animal. A magnitude da variável de decisão depende da relação entre duas estimativas de incidência: o intervalo entre experiências (I) e a demora do reforço ( $\mathrm{T}$ ). Esta variável é altamente abstrata, pois é uma relação entre duas relações. Ela é indiferente à escala de tempo, o que permite ao animal adaptar-se à variabilidade das circunstâncias no meio ambiente. o que importa é que haja a manutenção duradoura de uma proporção inalterada entre os valores de I e T. Este sistema de aprendizagem, visto assim, é um saber matemático, funcionalmente especializado, que atende às necessidades do animal de buscar a caça ou alimento de forma eficiente, 
pautando as suas ações de acordo com as contingências variáveis que se apresentam nas circunstâncias no mundo como ele é. Isto, para Gallistel, pode ser chamado de um órgão da mente. Gallistel expressa estranheza pela longa sobrevida das hipóteses behavioristas e conexionistas, que fazem ouvidos moucos às evidências empíricas fatais para estes modelos, cuja publicação está presente nas revistas especializadas desde os anos 70 .

\section{CONCLUSÃO}

O caráter orwelliano da situação está bem evidente: a natureza é pródiga em exemplos impressionantes de mecanismos relacionados a conhecimentos espécie-específicos e tarefa-específicos, e não evoluiu na direção de criar órgãos cognitivos multi-modais. No entanto, a teoria que "pegou", na academia e no grande público, hipotetiza um órgão de aprendizado - o condicionamento - que seria comum a todas as espécies e multi-modal.

Falta pouco para completar cinqüenta anos a teoria da gramática gerativa. Os aficionados dela somos uma magra minoria, apesar de, como vemos, ser esta teoria perfeitamente harmônica com os caminhos da etologia e dos estudos da evolução das espécies. Parece, portanto, que precisamos dar atenção ao caráter orwelliano da situação em que estamos imersos. Quem sabe o Orwell desta situação pode ter raiz em algum "problema de Platão"? Que mecanismo de sobrevivência é este, que nos causa desconforto quando se trata de acatar que não temos consciência de uma parte significativa daquilo que sabemos, pois são mecanismos gestados por caminhos secretos da natureza, e não se desnudam ao olhar raso que deseja coisas transparentes e controláveis? Contudo, afinal de contas, é uma meta sensata almejar saber como é o universo nas nossas entranhas.

\section{RESUMO}

Na década de noventa as áreas de estudos de cognição animal e cognição humana se fundamentam cada vez mais em uma teoria modular da arquitetura da mente: módulos cognitivos geneticamente determinados efetuam tarefas cognitivas específicas. $O$ trabalho de Noam Chomsky foi pioneiro em adotar essa concepção da mente ao abordar a capacidade humana de linguagem. Apesar da crescente evidência e argumentação cuidadosa, as teoria modularistas e inatistas da cognição em muitas espécies de animais e na espécie humana permanecem restritas ao universo acadêmico. Nesta fala vou resumir alguns estudos de comportamento animal que seguem uma lógica 
semelhante à dos princípios e parâmetros na lingüística, e tecer comentários sobre módulos da cognição de língua. o que causa o encapsulamento social desse tipo de informação? Esta é a questão que se propõe para o debate.

Palavras-chave: arquitetura modular das mentes; modularidede e inatismo; encapsulamento social de inatismomodularismo.

\begin{abstract}
Increasingly from the nineties, studies of animal and human cognition are based on an architecture of minds composed of multiple modules, genetically determined, and designed for certain specific cognitive tasks. Noam Chomsky's work was pioneer in adopting this kind of outlook in studies about human language capacity. In spite of abundant evidence and careful argumentation, innatist and modularist theories of cognition in animals and humans remain undisclosed and locked in the accademic universe. Here I will show a few examples of studies of animal behavior that follow the logic of principles and parameters. I will also comment on modules of human cognition that are being fruitfully studied and well understood. What causes the social encapsulation of this sort of information is the question left for debate. Key-words: modular architecture of minds; modularity and innatism; social encapsulation of innatism-modularism.
\end{abstract}

\title{
REFERÊNCIAS
}

CHOMSKY, Noam. Knowledge of Language, its nature, origin and use. New York: Praeger, 1996.

GALLISTEL, C. R. Frequency, contingency and the information processing theory of conditioning. In: SEDLMEIER, P.; BETSCH, T. (Eds.). Frequency processing and cognition. Oxford: Oxford University Press, 2002. p. 153-172.

Learning organs - to appear in French translation. In: BRICMONT, J.; FRANCK, J. (Eds.). Cahier: Noam Chomsky. 2006.

The replacement of general purpose learning models with adaptively specialized learning modules. In: GAZZANIGA, M. S. (Ed.). The Cognitive Neurosciences. 2. ed. Cambridge: MIT Press, 2000.

GENTNER, Timothy et al. Recursive syntactic pattern learning by songbirds, Nature, v. 440,2006

HAUSER, Marc; CHOMSKY, Noam; FITCH, W. Tecumseh. The Faculty of Language: What is it, Who has it and How did it evolve. Science 22, v. 298, n. 5598, p. 1569-1579, 2002. 